Thorax (1965), 20, 66.

\title{
Lower oesophagus lined with intestinal and gastric epithelia
}

\author{
LEON ABRAMS AND DONALD HEATH \\ From the Department of Thoracic Surgery, Queen Elizabeth Hospital, Birmingham, and the \\ Department of Pathology, University of Birmingham
}

\section{CASE REPORT}

The patient first had symptoms at the age of 14 years when he began to suffer from heartburn. This came on when he was lying down and was relieved when he sat up. Indigestion was also caused by eating pickles. The symptoms recurred intermittently and gradually grew worse. At the age of 24 years, while serving as a seaman in Malta, he began to experience burning pain in the epigastrium and he was admitted to hospital for investigation. A barium meal was reported as showing a normal stomach and duodenum, and passage of the barium through the remainder of the bowel was normal. He was treated by bed rest and alkalis. He felt better for about four years, but then in 1960 at the age of 30 years the symptoms recurred. Once again he began to suffer from heartburn which was aggravated by lying down and was usually experienced at night. In addition he complained of intermittent dysphagia of eight months' duration. At the time of admission to hospital he was able to swallow only fluids and semi-solids and as a result of this he had lost about 2 stones $(12.7 \mathrm{~kg}$.) in weight.

On examination he was a fit-looking man weighing 10 st. $9 \mathrm{lb}$. $(67.5 \mathrm{~kg}$.). A barium meal showed a stricture with a wide lumen just below the aortic arch (Fig. 1). Below this the oesophagus was wide and passed straight down into the stomach. In the erect position, after drinking approximately $200 \mathrm{ml}$. of barium meal, the stomach contents rose 2 in. $(5 \mathrm{~cm}$.) above the diaphragm on inspiration. When he lay down, the stomach contents ran straight up the oesophagus and only when they passed above the stricture did he experience heartburn. At oesophagoscopy it was noted that the oesophagus above the stricture was a little dilated and hyperaemic but was otherwise normal in appearance. The stricture itself (at $30 \mathrm{~cm}$.) was very red and bled easily. The oesophagoscope passed through it with ease. Below the stricture the mucosa was redder than above. At 37 $\mathrm{cm}$. the end of the oesophagoscope reached the cardia and passed into the stomach. Biopsies were taken at $24,27,30,33,37$, and $38 \mathrm{~cm}$.

Operation was carried out on 10 January 1961. The left lower chest was opened and the oesophagus looked entirely normal but for the fact that the cardia appeared to be at $37 \mathrm{~cm} ., 3 \mathrm{~cm}$. above the right crus. This was judged by the change from the rather rough longitudinal muscle to a smooth stomach wall, and by the attachment of the peritoneum. The limbs of the right crus were widely divaricated. An incision was made in the diaphragm to allow inspection of the stomach. This was normal in size, shape, and position apart from the small hiatus hernia. On palpating the oesophagus in the region of the aortic arch there was a soft, mobile mucosal thickening. A repair of the hiatus hernia was carried out, the limb of the right crus being sutured in front of the oesophagus. There was immediate relief of the dysphagia and heartburn after the operation. A postoperative barium meal showed no hold-up, and it was not possible to provoke reflux by the usual manœuvres.

After operation he gained $1 \frac{1}{2}$ stones $(9.5 \mathrm{~kg}$.) in weight. A barium swallow on 20 June 1961 showed

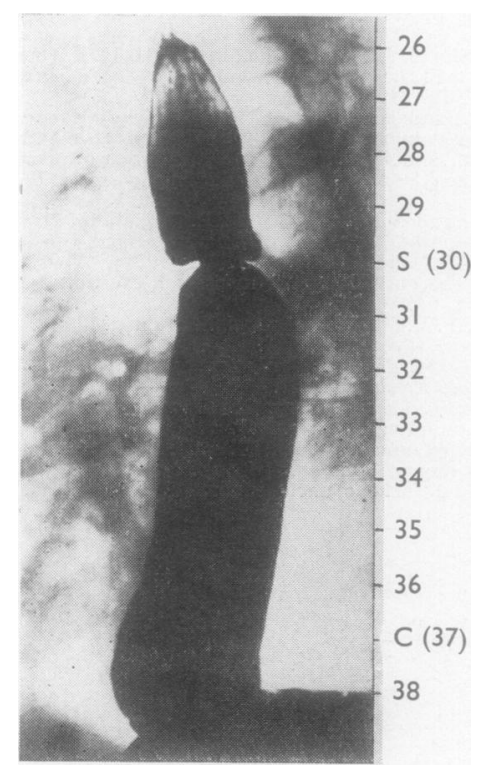

FIG. 1. Barium swallow showing the stricture at $30 \mathrm{~cm}$., the dilatation of the oesophagus, and the position of the cardia. 
a little residual narrowing of the oesophagus 2 in. $(50.8 \mathrm{~mm}$.) below the aortic arch. There was no evidence of reflux of barium into the oesophagus.

Later his symptoms recurred, and, when seen on 18 November 1962, he had slight difficulty in swallowing, together with regurgitation and heartburn. The retrosternal burning pain was worse at night when he was lying down and when he bent forwards. It was also aggravated by drinking beer. He was readmitted on 23 February 1963 for further investigation. A barium meal showed that the cardia was at hiatal level but it was incompetent and allowed some gastrooesophageal reflux. Oesophagoscopy was carried out and biopsies were taken at 19, 23, 29, 33, 37, and 40 cm. The stricture could not be identified. He was advised to lose weight and did so, becoming symptomfree in three months.

\section{HISTOLOGY OF THE BIOPSIES}

The epithelia seen in the biopsies were of three distinct types.

ABOVE 30 CM. These biopsies were lined by stratified squamous epithelium (Fig. 2). Muscularis mucosae was present in three of the five biopsies. Oesophageal mucous glands were present both deep and superficial to the muscularis. The secretion in these glands stained positively with alcian blue but not with periodic acid Schiff (P.A.S.). In

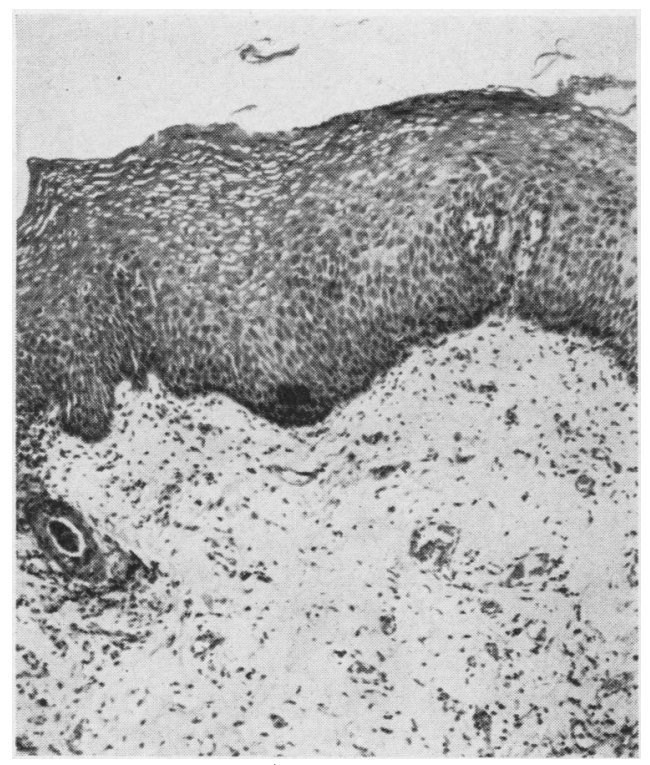

FIG. 2. Biopsy at $24 \mathrm{~cm}$. The epithelium is of the stratified squamous variety such as lines the normal oesophagus. $H$. and $E$., $\times 100$. three of the biopsies the submucosal layer was infiltrated with lymphocytes.

AT $30 \mathrm{CM}$. This biopsy was lined by villous epithelium (Fig. 3a). The cells of the lining surface epithelium and of the deeper glands were mucussecreting, and many had the appearance of goblet cells (Fig. 3b). The secretions within these cells stained strongly positive with both alcian blue and P.A.S. The cells of the surface epithelium had a brush border which stained with P.A.S. and which was easily demonstrated in polarized light (Fig. 3c). Numerous argentaffin cells were interspersed between the secretory cells of the glands (Fig. 3d). Muscularis mucosae was included in this biopsy, and the substantia propria was heavily infiltrated with eosinophils, lymphocytes, and plasma cells. No Paneth cells were seen.

AT AND BELOW $33 \mathrm{~cm}$. Surface epithelium lining glandular pits and an underlying layer of simple tubular glands were both present (Fig. 4a). Villi were not seen in any of these biopsies. The surface epithelium was composed of simple, mucussecreting cells (Fig. 4b), the contained mucins staining strongly with P.A.S. but very faintly or not at all with alcian blue. The cells of the deeper glandular layer were of different types (Fig. 4c). Mucous neck cells were present, the contained mucins staining positively with P.A.S. but not with alcian blue. Parietal (oxyntic) cells were also readily identifiable by their bright eosinophilia and their intracellular canals (Fig. 4c). There was no suggestion of a brush border in the cells of this third group of biopsies. Argentaffin cells were present but scanty. Muscularis mucosae was included in all the biopsies, and in each instance there was an exudate of lymphocytes, eosinophils, and plasma cells in the substantia propria.

In the biopsy taken at $38 \mathrm{~cm}$. (Fig. 4d) the demarcation between surface epithelium lining glandular pits and a well-marked deeper glandular layer was so sharp and characteristic as to leave no doubt that this biopsy had been taken from the stomach proper.

NATURE OF THE BIOPSIES AT VARIOUS SITES The biopsies taken above the level of $30 \mathrm{~cm}$. from the upper incisor teeth were lined by epithelium obviously of the squamous type which is normally found in the oesophagus (Fig. 2).

The epithelium at the $30 \mathrm{~cm}$. level was intestinal in type and comparable to that lining the small bowel. This is indicated by its villous nature (Fig. 3a) and the presence of a brush border (Fig. 3c) which is absent from gastric epithelium. 


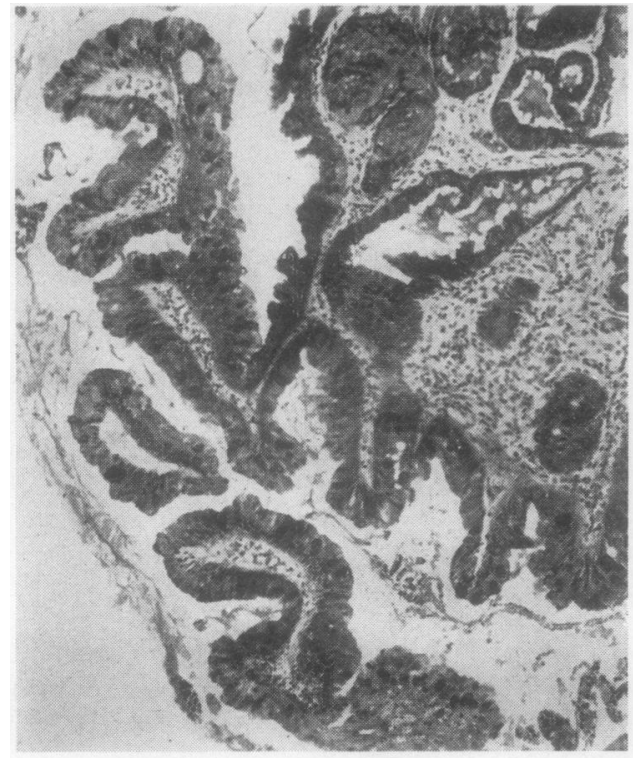

(a)

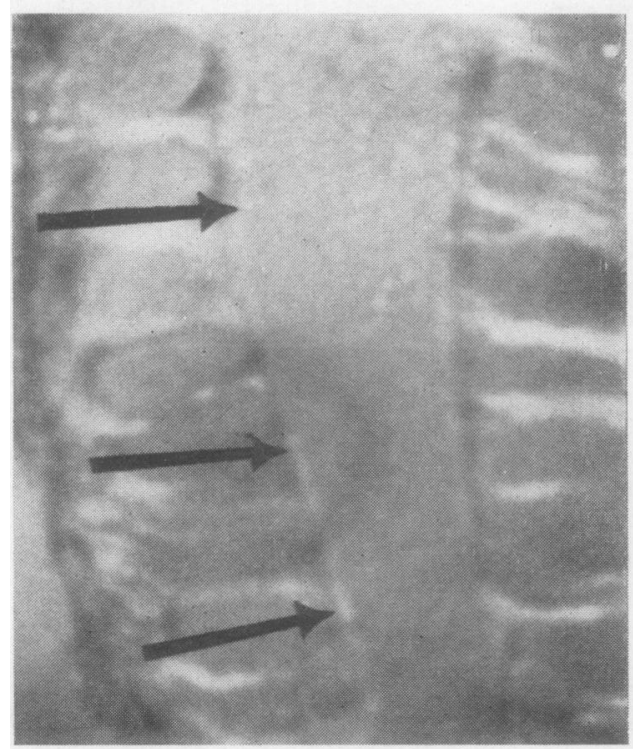

(c)

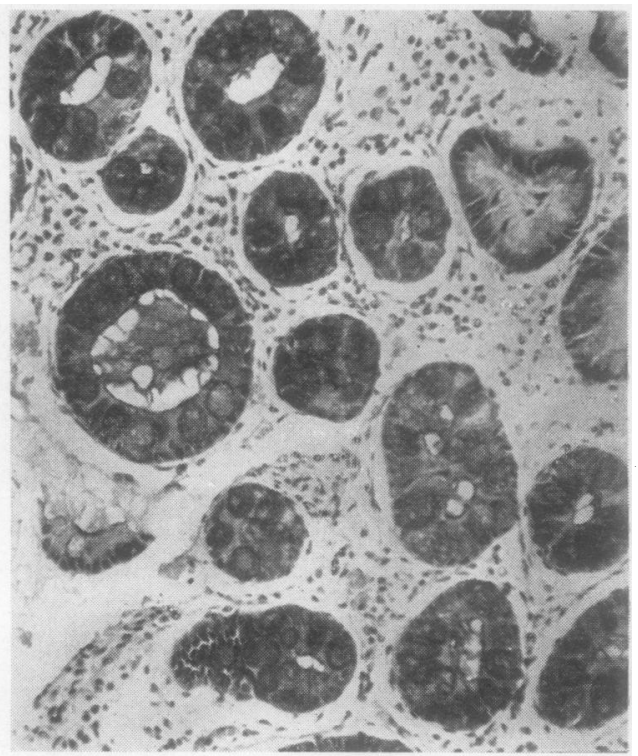

(b)

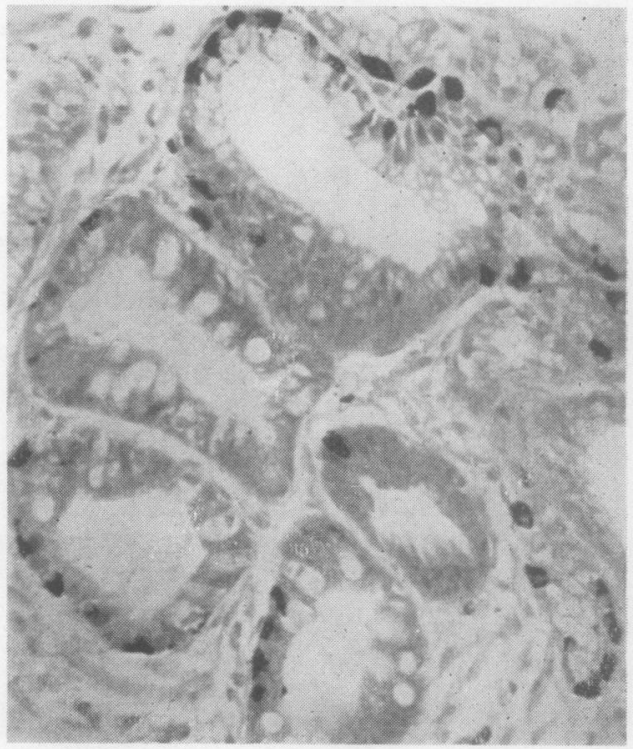

(d)

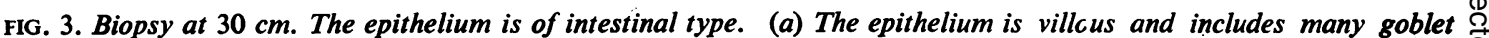
cells. $H$. and $E ., \times 100$. (b) The deeper glandular layer contains numerous goblet cells. $H$. and $E ., \times 150$. (c) The $\stackrel{\mathbb{Q}}{\varrho}$ surface epithelium has a prominent brush border (arrows). Unstained section in polarized light. (d) Intersfersed between $\sigma$ the mucus-secreting elements are numerous argentaffin cells. Silver stain, $\times 250$. 


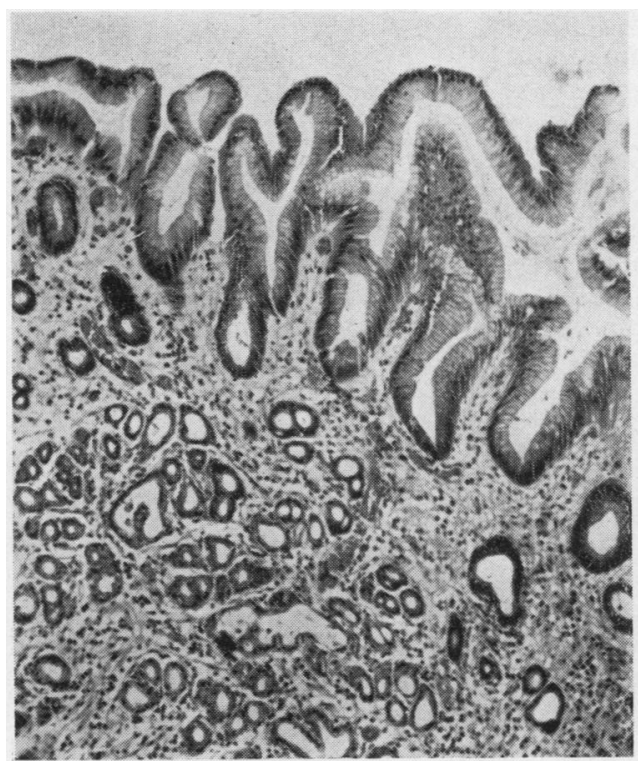

(a)

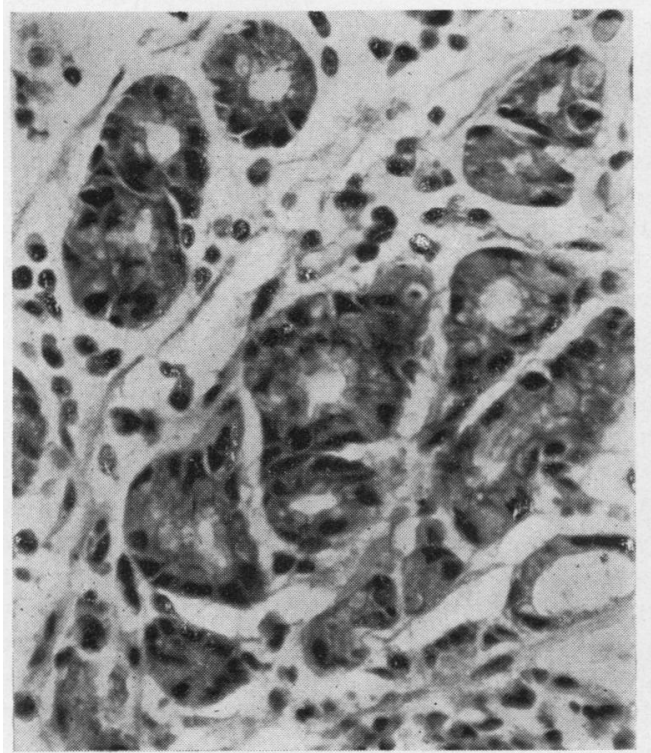

(c)

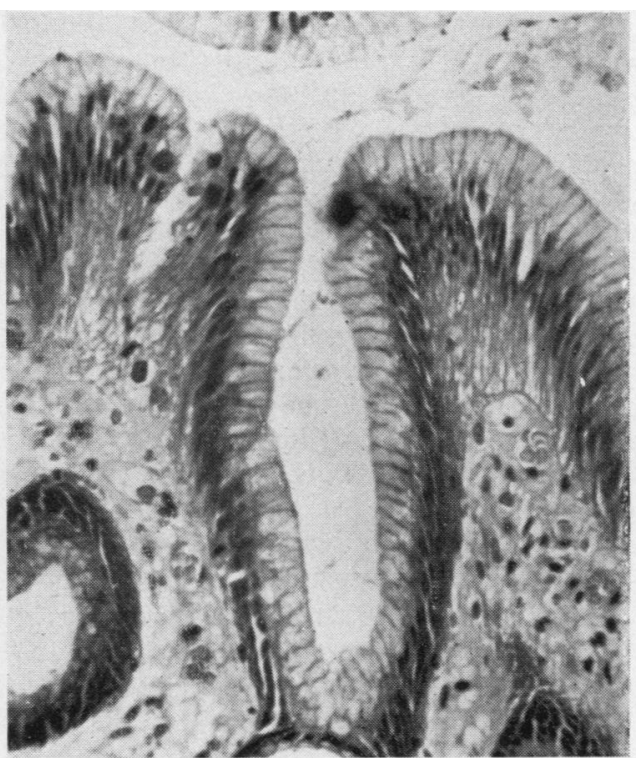

(b)

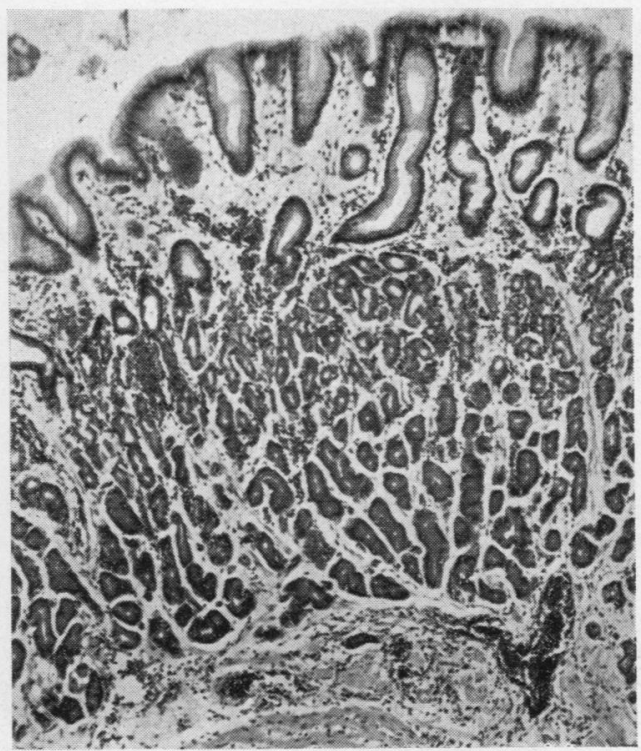

(d)

FIG. 4. Biopsy at $33 \mathrm{~cm}$. The epithelium is of gastric fundal type. (a) The biopsy is lined by mucus-secreting surface epithelium and includes a deeper glandular layer. $H$. and $E ., \times 100$. (b) The mucus-secreting surface epithelium. $H$. and $E ., \times 100$. (c) The deeper glandular layer includes oxyntic cells. $H$. and E., $\times 450$. (d) Biopsy at $38 \mathrm{~cm}$. The surface epithelium and deeper glandular layer are so well developed and demarcated from one another as to suggest that this tissue has come from the gastric fundus proper. $H$. and $E ., \times 75$. 
In addition there were numerous argentaffin cells (Fig. 3d) which are common in the small and large intestine but scanty in the human stomach (Hamperl, 1952). The staining reactions were also more like those of intestine than of stomach and they clearly differed from the tinctorial properties of the third, lowermost group of biopsies.

The latter biopsies taken at or below $33 \mathrm{~cm}$. showed features characteristic of gastric epithelium with mucus-secreting surface epithelium, gastric pits, and a deeper glandular layer (Fig. 4a). Also characteristic were the absence of villi, the scanty number of argentaffin cells, and the staining reactions of the mucins. It is possible to take identification further in this third group since the different types of cell, including oxyntic cells, in the deeper glandular layer (Fig. 4c) indicate that the gastric epithelium is of fundal rather than cardiac type. The existence of many oxyntic cells with prominent intracellular canals suggests that this epithelium was capable of secreting hydrochloric acid.

The biopsies taken at or below $38 \mathrm{~cm}$. are so characteristic of fundal type gastric epithelium as to suggest that they have been taken from the fundus of the stomach proper, situated below the cardia but in the mediastinum above the level of the diaphragm, having slid through a hiatus hernia (Fig. 4d).

\section{DISCUSSION}

The studies of Allison and Johnstone (1953) and of Barrett (1957) have demonstrated a distinct pathological entity in which the lower oesophagus is lined by glandular instead of squamous epithelium. This condition is distinct from a sliding hiatus hernia in which such gastric mucosa as is present above the diaphragm is due simply to bodily displacement of the stomach through the hiatus. Confusion in the past has arisen because the two conditions commonly co-exist (Allison and Johnstone, 1953). It also follows that peptic ulceration of the lower oesophagus may be due in the case of an uncomplicated sliding hiatus hernia to the action of acid digestive juice from the stomach on squamous epithelium by the mechanism of 'reflux oesophagitis' through an incompetent cardia (Allison, 1948). On the other hand, in the case of lining of the lower oesophagus by gastric mucosa the ulcer may be a true gastric ulcer ('Barrett's ulcer') (Allison and Johnstone, 1953).

Allison and Johnstone (1953) made the suggestion that the lining of the lower oesophagus by glandular epithelium might be due to an incompetence of the cardia which may or may not have its origin in a hiatus hernia. They pointed out that a patient with an incompetent cardia has the lower end of the oesophagus $\frac{\bar{\omega}}{\bar{\phi}}$ constantly bathed in acid gastric secretions. They $\mathbb{\Phi}$ thought that in a patient in whom this had produced oesophagitis with destruction of $\rightarrow$ squamous epithelium any consequent healing in the presence of gastric juice might occur more $\overrightarrow{\vec{\omega}}$ readily by an upgrowth of gastric epithelium $\stackrel{\circ}{\circ}$ rather than by a downgrowth of squamous epi- $\vec{x}$ thelium. Morris (1955) thought this was an attractive theory as it explained the late onset of symptoms in patients who had developed a hiatus hernia only in their middle age. On the other hand, the onset of symptoms in this condition $\frac{}{2}$ sometimes occurs much earlier, as in the present case where the patient first had heartburn at the age of 14 years. Such early symptomatology is more readily explained by the alternative hypothesis of Allison and Johnstone (1953) that the epithelium lining the lower oesophagus is hetero- of topic and congenital in origin. This concept is also supported by the complex changes that occur in the types of epithelium lining the oesophagus during its development. The simple epithelium lining the primitive foregut proliferates to form in the oesophagus of the six-weeks embryo a multi-layered epithelium surrounding a relatively small lumen (Johns, 1952; Willis, 1958). This is followed by a short stage when the epithelium assumes a simple columnar form with nuclei at the apices of the cells (Raeburn, 1951; Willis, 1958). Beneath this is a basal layer of cubical or spheroidal cells (Raeburn, 1951). During the tenth week the epithelium becomes pseudostratified and the surface cells become ciliated. This change is so extensive that during the fourth and fifth months the greater part of the lining of the oesophagus is composed of ciliated epithelium (Willis, 1958). Patchy loss of ciliated cells then occurs. Glycogen-containing vesicular cells appear in the basal layer (Raeburn, 1951), and these gradually change to a stratified squamous type. At the same time the columnar cells atrophy and desquamate. Mature stratified squamous epithelium is present by the sixth month, the change being most advanced in the middle third of the oesophagus (Johns, 1952 ; Willis, 1958).

There have been several reports of the persistence of such embryonic, ciliated epithelium in the oesophagus. Ciliated columnar epithelium has been recorded as occurring in a seven-month foetus by Healey (1920) and in premature and newborn infants by Rector and Connerley (1941), who found it in 42 of the 118 of their 1,000 consecutively necropsied infants and children who 
showed some form of aberrant mucosa in the oesophagus. Ciliated epithelium has even been reported as lining multiple large areas of the lower half of the oesophagus in a woman aged 35 years by Raeburn (1951).

The problem is made even more complex by the fact that the oesophagus may be lined not only by persistent epithelium of a type found normally during its embryonic development but also by gastric mucosa. The presence of such gastric mucosa in the oesophagus seems to have a basis in the caudal descent of the stomach before the seventh week of foetal life when a few nests of cells that are destined to become gastric mucosa remain in the oesophageal portion of the gut and become islets of typical gastric mucosa (Rector and Connerley, 1941). According to these authors, heterotopic gastric mucosa was described as long ago as 1805 by Schmidt. It appears to be a very common anomaly. Schridde (1904) found patches of heterotopic gastric mucosa up to $2 \mathrm{~cm}$. in diameter in the postcricoid region of the oesophagus in $70 \%$ of his necropsied cases. Rector and Connerley (1941) found 78 cases of heterotopic gastric mucosa in the oesophagus in 1,000 consecutive necropsies in children.

There has been a great deal of discussion as to the type of gastric mucosa that occurs in such an ectopic site. Barrett (1957) recognized that the problem was not academic since the presence or absence of oxyntic cells with their capacity for the secretion of hydrochloric acid was probably of considerable importance in the aetiology of chronic peptic ulcer of gastric type in the lower oesophagus lined by heterotopic epithelium ('Barrett's ulcer'). He stated that the important point at issue was whether the abnormal epithelium in the oesophagus was 'gastric', implying fundal, or 'plain columnar'. He thought that the heterotopic epithelium consisted of columnar cells, arranged in shallow tubular glands among which were mucus-secreting units, and he believed such mucosa to resemble the deep oesophageal glands. At the same time he believed that lower in the oesophagus the simple tubular epithelium gave place to more typical gastric mucosa with scattered oxyntic cells. Allison and Johnstone (1953), however, thought that the mucosa was gastric and of cardiac type from which oxyntic cells are of course absent. This view had been held originally by Schridde (1904), who described the heterotopic epithelium as consisting solely of mucus-secreting columnar epithelium and resembling cardiac gastric mucosa. Rector and Connerley (1941) found cardiac-type gastric mucosa with no oxyntic cells in 63 of their 78 cases. Bosher and Taylor (1951) also described the heterotopic epithelium in their cases as being of cardiac gastric type. Histological findings of this sort suggested to Barrett (1957) that the abnormal epithelium, despite its looks, did not function exactly as stomach and probably secreted little acid digestive juice. Its secretions were therefore probably of little or no significance in the development of chronic peptic ulcer of gastric type in the lower oesophagus, which was more likely to be related to 'reflux oesophagitis' (Allison, 1948) in these cases.

However, while the heterotopic gastric mucosa in some examples of this condition has undoubtedly been of cardiac type, it is quite wrong to assume that this is always the case. Rector and Connerley (1941) were of the opinion that whether such islands contain oxyntic cells depends primarily on the particular portion of the primordial fusiform gastric swelling from which they originated. The level of the oesophagus at which they are found depends on their final level of descent in the course of the elongation of the oesophagus concomitant with the descent of the stomach. They found oxyntic cells in 26 of their 78 cases of heterotopic gastric mucosa in the oesophagus of children. Stewart and Hartfall (1929) studied a case of chronic peptic ulcer of the oesophagus and found two large patches of gastric mucosa in the oesophagus which were comprised of typical fundal type gastric mucosa with abundant oxyntic cells. They thought there could be little doubt that this mucosa was capable of secreting acid gastric juice. The biopsies taken at and below $33 \mathrm{~cm}$. in the present case are also of typical fundal type with many oxyntic and fewer argentaffin cells. Willis (1958) accepts that there have been many reports of typical fundal gastric mucosa lining the oesophagus.

An interesting additional feature of the present case is the patch of intestinal mucosa within the oesophagus. We have found no previous reference to this occurrence, but it is not an altogether unexpected finding. Intestinal metaplasia in chronically inflamed or ulcerated gastric epithelium is known to be common (Magnus, 1937), and there seems no reason why such metaplasia should not occur just because the gastric epithelium lines the oesophagus instead of the stomach. Such metaplastic mucosa may be histologically identical with normal intestinal epithelium (Magnus) so that the well-differentiated nature of the epithelium in the present case does not deny its origin in metaplasia rather than in heterotopia. Willis (1958) accepts that the once prevalent view that the presence of typical 
intestinal epithelium in gastric mucosa was due to developmental heterotopia is now totally abandoned.

\section{SUMMARY}

A seaman aged 30 years complained of dysphagia after a long history of heartburn aggravated by lying down. He proved to have a hiatus hernia and an oesophageal stricture. The oesophagus was lined with intestinal epithelium at the stricture and with gastric epithelium of fundal type below it. The nature of this abnormality is discussed.

\section{REFERENCES}

Allison, P. R. (1948). Peptic ulcer of the oesophagus. Thorax, 3, 20. and Johnstone, A. S. (1953). The oesophagus lined with gastric mucous membrane. Ibid., 8, 87.
Barrett, N. R. (1957). The lower esophagus lined by columnar epithelium. Surgery, 41, 881 .

Bosher, L. H., and Taylor, F. H. (1951). Heterotopic gastric mucosa in the esophagus with ulceration and stricture formation. J. thorac. Surg., 21, 306.

Hamperl, H. (1952). ('ber argyrophile Zellen. Virchows Arch. path. Anat., 321, 482 .

Healey, F. H. (1920). Note on the occurrence of ciliated epithelium in the oesophagus of a seventh month human foetus. J. Anat. (Lond.), 54, 180.

Johns, B. A. E. (1952). Developmental changes in the cescphageal $\vec{O}$ epithelium in man. Ibid., 86, 431.

Magnus, H. A. (1937). Observations on the presence of intcstinal epithelium in the gastric mucosa. J. Path. Bact.. 44, 389.

Morris, K. N. (1955). Gastric mucosa within the oescphagus. Aust. N.Z. J. Surg., 25, 24. Aust. N. (1951). Columnar ciliated epithelium in the adult oeso-
phagus. J. Path. Bact., 63, 157 .

Rector, L. E., and Connerley, M. L. (1941). Aberrant mucosa in the N esophagus in infants and in children. Arch. Path., 31, 285.

Schridde, H. (1904). t'ber Magenschleimhaut. Inse In vom Eau der Cardialdrüsenzone und Fundusdrüsenregion und den unteren, oesophagealen Cardialdrüsen gleichende Diüsen im obersteno oesophagealen Cardialdrüsen gleichende Di üsen im oberstenO

Oesophagusabschnitt. Virchows Arch. path. Ar.at., 175, 1 .
Stewart, M. J., and Hartfall, S. J. (1929). Chronic peptic ulcer of the oesophagus. J. Path. Bact., 32, 9.

Willis, R. A. (1958). The Borderland of Embryology and Pathology. Butterworth, London. 